\title{
Comparison between laparoscopic and conventional technique in the surgical treatment of choledocholithiasis
}

\author{
Mehmet Can Aydın, ${ }^{\circ}$ Servet Rüştü Karahan, ${ }^{2}$ Emin Kose ${ }^{2}$ \\ 'Department of General Surgery, İnönü University, Malatya, Turkey \\ ${ }^{2}$ Department of General Surgery, University of Health Science Prof.Dr. Cemil Taşçığlu State Hospital, Istanbul, Turkey
}

\begin{abstract}
Introduction: The aim of the study is to compare $\mathrm{f}$ conventional and laparoscopic techniques in common bile duct exploration in terms of efficacy and safety.

Materials and Methods: The data of 280 patients who underwent surgical procedure for common bile duct stones between January 2011 and December 2016 were retrospectively analyzed. This was an Ethics Committee-approved retrospective analysis of data between 2011 and 2016. The patients were divided into two groups according to the common bile duct exploration technique: laparoscopic (Group 1, 164 patients) and conventional (Group 2, 116 patients). The two groups were compared in terms of surgical findings and short-term results.

Results: $170(60.7 \%)$ of the patients were women. The mean age was $61.9 \pm 16.9$ years. Clinical results showed that the operative time $(120 \pm 35.9$ vs $169 \pm 48.4$ minutes, $p<0.01)$ and hospital stay $(6.3 \pm 3.9$ vs $10.9 \pm 6.8$ days, $p<0.01)$ were shorter in Group 1; overall morbidity ( $9 \%$ vs $24 \%, p<0.01)$ and mortality rates $(1.2 \%$ vs $6 \%$, $p<0.03)$ were lower. Postoperative endoscopic sphincterotomy requirement was less $(7 \%$ vs $18.1 \%, p<0.01)$. In addition, in Group 1, there was a higher rate of stone clearance $(93.9 \%$ vs $82.8 \%, p<0.01)$ with a lower rate of wound infection $(0.6 \%$ vs $10.3 \%, p<0.01)$. No difference was observed in terms of re-operation, bile leakage or drain dislocation.

Conclusion: In terms of stone clearance, hospital stay, morbidity, mortality and complication rates, laparoscopic common bile duct exploration is a significantly safer and more effective method compared to conventional exploration.
\end{abstract}

Keywords: Choledocholithiasis; conventional common bile duct exploration; laparoscopic common bile duct exploration.

\section{Introduction}

Gallstones are one of the most common problems of the digestive system and their prevalence ranges from $11 \%-36 \%$. In $6 \%-12 \%$ of patients with gallstones, common bile duct
(CBD) stones are also found and in patients with symptomatic gallstones over the age of $60,20 \%-25 \%$ also have CBD stones that require additional treatment. ${ }^{[1]}$ Today, as well as cholecystectomy+endoscopic retrograde cholangiopancreatography (LC+ERCP), conventional common 
bile duct exploration (CCBDE) (Choledochotomy+T-tube) and laparoscopic common bile duct exploration (LCBDE) can all be used in the treatment of CBD stones. ${ }^{[2]}$

LCBDE is now a far more common approach, as laparoscopic techniques become more common and morbidity rates drop due to advances in technology and treatment outcomes are seen to be equal or better. ${ }^{[3]}$ However, in the treatment of CBD stones, ERCP is still the most preferred treatment method although related complications such as pancreatitis, hemorrhage and duodenum perforation as well as the possibility of causing permanent sphincter malfunction lead to high morbidity rates. ${ }^{[4]}$ In addition, LCBDE is becoming increasingly common as a one-step surgical option, compared to the conventional two-step (LC+ERCP) treatment.

Similar studies in the literature have found LCBDE to be more successful than CCBDE in terms of morbidity rate and hospital stay. Moreover, our study showed that LCBDE was also more successful in stone extraction, while reducing general complication and mortality rate sand the necessity for postoperative sphincterotomy. ${ }^{[5]}$

Due to these significant advantages, our aim in this study is to propose that LCBDE be adopted as the primary surgical approach rather than merely be seen as an alternative method to CCBDE.

\section{Materials and Methods}

A total of 280 patients who underwent LCBDE ( $n=164$, 58.5\%) and CCBDE ( $n=116,41.4 \%)$ for CBD stones, in the general surgery clinic at the University of Health Science Prof.Dr. Cemil Taşçığlu State Hospital between January 2011 and December 2016, were evaluated in this study. This was an Institutional Review Board (IRB) approved (22.11.2016/546) retrospective analysis of prospective data base between 2011 and 2016. Patients with CBD stones diagnosed via preoperative imaging methods and who underwent either emergency or elective surgery were all included in the study. The groups were compared with regard to demographic, preoperative, perioperative and early post-operative data collected from their patient files. Patients with no CBD stones in their preoperative imaging or with malignant obstructions were excluded from the study.

\section{Laparoscopic Common Bile Duct Exploration}

Choledochoscopy can be performed in two ways: tran- scystic or through a choledochotomy. To perform the first method, a medium size (10Fr, $3.3 \mathrm{~mm}$ ) flexible or rigid choledochoscope is used while a larger size (15 Fr, 5.5 $\mathrm{mm}$ ) is needed for the second. In our clinic, for technical reasons, a rigid choledochoscope was used on all patients (Fig. 1). With the Hasson technique, the first trocar (10mm) was inserted through the umbilicus and $12 \mathrm{mmHg}$ pneumoperitoneum was created. Then, 2 trocars $(5 \mathrm{~mm}$ each) were inserted; one from the right anterior axillary line to the subcostal intersection point, and one from the right lateral side of the umbilicus to the midclavicular intersection point. In addition, a 10mm trocar was inserted from the intersection point of the left midclavicular line and the left subcostal. To place the rigid choledochoscope, a $5 \mathrm{~mm}$ trocar was inserted from the epigastric region and the upper right part of the xiphoid. After the ductus cysticus and cystic artery were dissected, the ductus cysticus was clipped; the cystic artery was clipped and transected. Choledochotomy was performed under the guidance of ductus cysticus, with a $0,5-1 \mathrm{~cm}$ vertical incision from the supraduodenal section. The choledochus was washed and the calculus, microcalculi and any particles were extracted (Fig. 2). The proximal and distal bile ducts were visualized via the epigastric trocar and the $5 \mathrm{~mm}$ trocar in the right lateral part of the umbilicus. In all patients, the transition to the duodenum was made in the distal duct, while the right and left hepatic canals were visualized and recorded from the proximal duct. The detected stones were extracted with the help of irrigation, Fogarty balloon catheter and Dormia basket catheter (Fig. 3). An internal stent was placed in patients with cholangitis, pancreatitis and those with more than 5 stones. The choledochotomy line was closed with primary sutures, concluding the cholecystectomy.

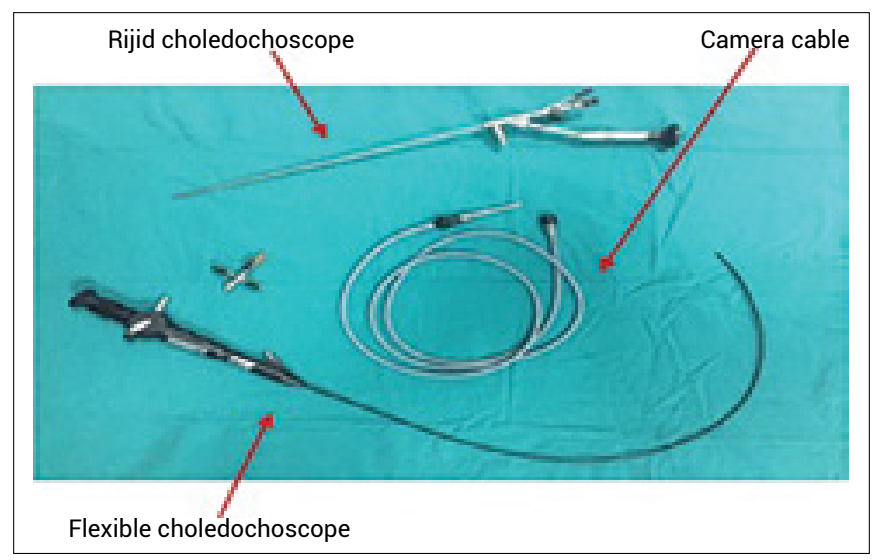

Figure 1. Flexible and rigid choledochoscope. 


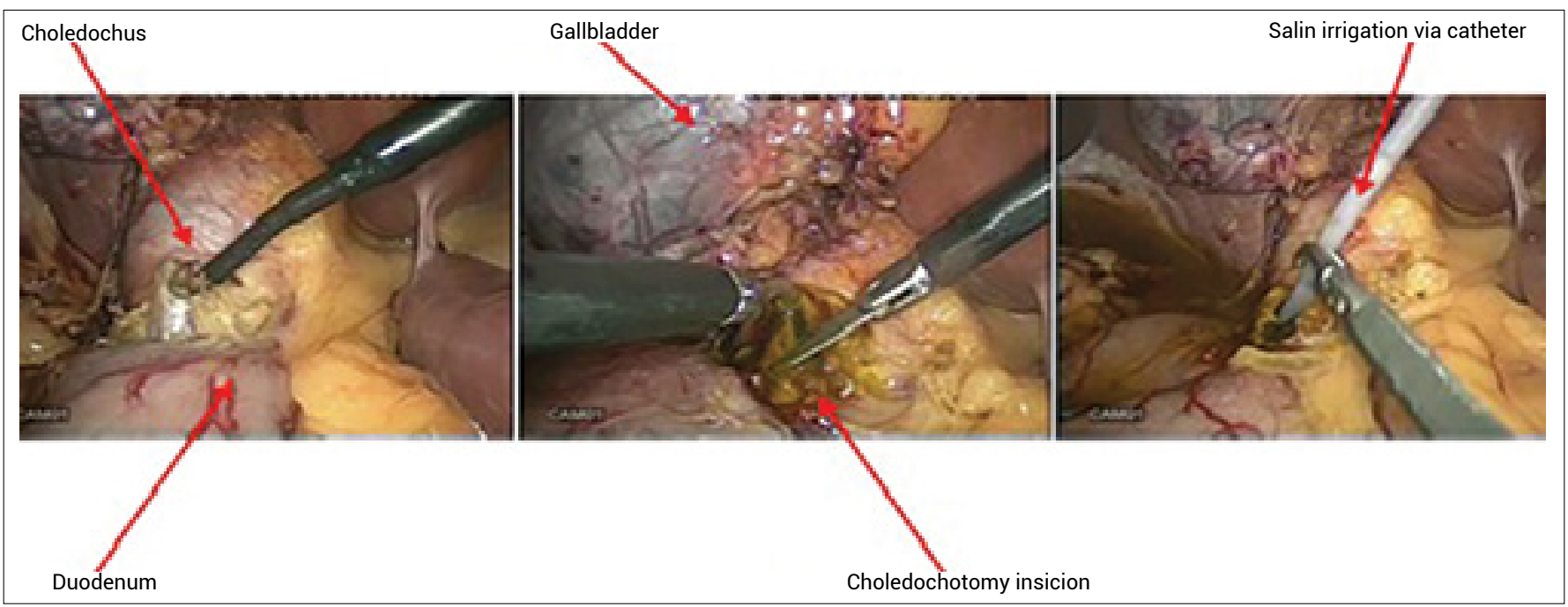

Figure 2. Choledochotomy incision from the supraduodenal section and salin irrigation via catheter.

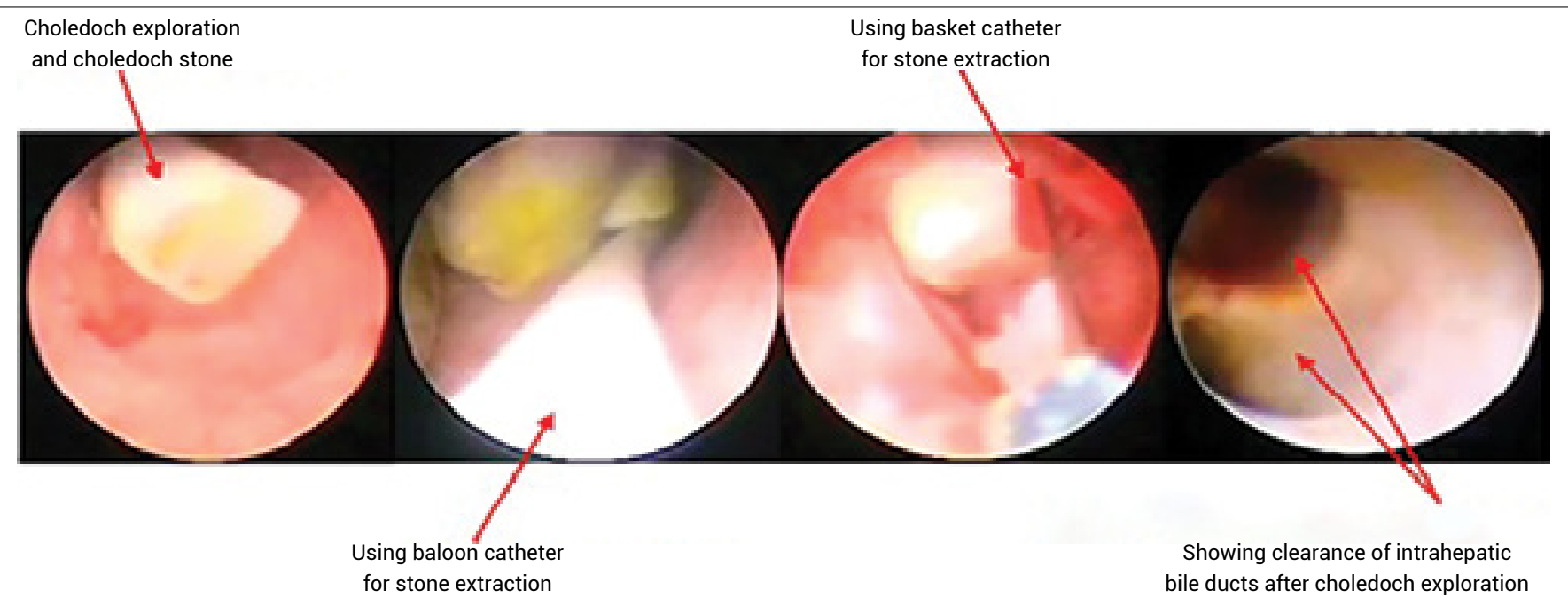

Figure 3. Exploration of common bile duct after stone extraction with baloon and basket catheter.

\section{Conventional Common Bile Duct Exploration}

Following the right subcostal incision, similar to the LCBDE surgery technique, a vertical choledochotomy was performed by dissecting a $1-2 \mathrm{~cm}$ area in the front of the supraduodenal section. A Fogarty balloon catheter, Dormia basket catheter and forceps were used to retrieve the stones. The choledochotomy line was closed by primary suture with a cystic cannula, choledochoduodenostomy and choledochojejunostomy or by placing a T-tube. Patients with an external drainage catheter were evaluated perioperatively for leakage and any remaining stones by cholangiography. Following the operation, a T-tube was placed for drainage. A few days later, the bile duct was evaluated with a T-tube cholangiography; the T-tube was removed two weeks later.

\section{Statistical Analysis}

Statistical analysis was carried out using SPSS 15.0 version (SPSS Inc., Chicago, IL, USA). To evaluate the significant differences between groups, Chi square, Mann Whitney U, Kruskal-Wallis and Benferroni-revised Mann-Whitney $\mathrm{U}$ tests were used. Those with $\mathrm{p}<0.05$ were considered statistically significant.

\section{Results}

$170(60.7 \%)$ of the patients were female and $110(39.3 \%)$ were male, with a mean age of $61.9 \pm 16.9$. Demographic data and clinical features of the patients are summarized in Table 1. Patients diagnosed with asymptomatic CBD stones, cholangitis, pancreatitis and jaundice were operated on. There was no statistical difference between 
Table 1. Demographic data and clinical features of the patients

\begin{tabular}{|c|c|c|c|}
\hline & LCBDE & CCBDE & $\mathbf{p}$ \\
\hline Age,median (range) & $57.5(21-95)$ & $65.5(25-105)$ & 0.001 \\
\hline Gender(F/M), n (\%) & $114(70) / 50(30)$ & $56(48) / 60(52)$ & $<0.05$ \\
\hline ASA I-II/III-IV, n (\%) & $157(96) / 7(4)$ & $104(90) / 12(10)$ & 0.05 \\
\hline $\mathrm{BMI}(\leq 30 />30), \mathrm{n}(\%)$ & $130(79) / 34(21)$ & $99(85) / 17(15)$ & $>0.05$ \\
\hline Diagnosis (emergency/elective), n (\%) & $62(38) / 102(62)$ & $56(48) / 60(52)$ & 0.08 \\
\hline Size of CBD stone, $\mathrm{mm} / \mathrm{cm}, \mathrm{n}(\%)$ & $120(73.2) / 44(26.8)$ & $82(70.2) / 34(29.8)$ & 0.648 \\
\hline Number of CBD stones, single/multipl, n (\%) & $85(51.8) / 79(48.2)$ & $60(51.7) / 56(48.3)$ & 0.986 \\
\hline
\end{tabular}

LCBDE: Laparoscopic common bile duct exploration; CCBDE: Conventional common bile duct exploration.

patients who received elective or emergency surgery $(\mathrm{p}=0.08)$. There were 51 patients $(18.2 \%)$ with median, subcostal or trocar entry incisions related to upper abdominal surgery history (cholecystectomy, total or subtotal gastrectomy, liver cyst hydatid operation, hiatal hernia repair, gastroesophageal reflux operation) and CCBDE was preferred more in these patients $(\mathrm{p}<0.05)$.

In all patients, CBD stones were detected preoperatively by Ultrasonography (USG) or more commonly with Magnetic Resonance Cholangiopancreatography (MRCP). Stones in the CBD were classified as millimetric/centimetric and single/multiple. There were no differences between the groups in terms of number and size of the stones $(\mathrm{p}=0.6, \mathrm{p}=0.9)$. The median bile duct diameter was $12.3 \pm 4.9 \mathrm{~mm}$ in the laparoscopic group and $13.4 \pm 4.6 \mathrm{~mm}$ in the conventional group; the mean CBD diameter was larger in patients who underwent CCBDE ( $\mathrm{p}=0.02)$. 56 patients $(20 \%)$ had previously received endoscopic sphincterotomy. Sphincterotomies were planned independently of these operations; there was no fixed time between the two procedures. Patients who underwent sphincterotomy prior to the exploration were also more common in the conventional group $(\mathrm{p}=0.008)$.

With regard to biliary reconstruction techniques of the patients, primary suturing was the principal tecnique in the laparoscopic group (70.7\%), while in the conventional group, closure with the use of a T-tube (67.2\%) was preferred (Table 2). All patients who had not undergone cholecystectomy previously, received one simultaneously. Although all operations started laparoscopically, 33 patients' operations were converted to open surgery due to various reasons (16.7\%). These reasons were as follows: difficulty in clear evaluation of anatomical structure; advanced secondary adhesions caused by prior operation which restricted dissection; and adhesions in the region

\begin{tabular}{lccccc}
$\begin{array}{l}\text { Table 2. Localization of common bile duct stones in } \\
\text { preoperative imaging }\end{array}$ & \multicolumn{2}{c}{$\begin{array}{c}\text { LCBDE } \\
(\mathbf{n}=164)\end{array}$} & & \multicolumn{2}{c}{$\begin{array}{c}\text { CCBDE } \\
(\mathbf{n}=116)\end{array}$} \\
\cline { 2 - 3 } & $\mathbf{n}$ & $\%$ & & $\mathbf{n}$ & $\%$ \\
\hline Distal of CBD & 132 & 80.4 & 88 & 75.8 \\
Middle of CBD & 2 & 1.2 & 6 & 5.2 \\
Proksimal of CBD & 1 & 0.6 & 4 & 3.4 \\
Intrahepatic bile ducts & 1 & 0.6 & 2 & 1.7 \\
Common of CBD & 28 & 17 & 16 & 13.8 \\
\hline
\end{tabular}

LCBDE: Laparoscopic common bile duct exploration; CCBDE: Conventional common bile duct exploration.

due to previous or current cholecystitis attacks.

In the LCBDE group, the average operation time was shorter (120 vs169 min, $\mathrm{p}<0.01$ ) and the morbidity rate was lower (9.1\% vs $24 \%, \mathrm{p}<0.01)$. Complications related to this operation were drain dislocation, pancreatitis, retained bile duct stones, bleeding, bile leakage and wound infection; the LCBDE group had a generally lower complication rate $(12.8 \%$ vs $36.2 \%, p<0.01)$, as well as a lower rate of retained stones $(6.1 \%$ vs $17.2 \%, \mathrm{p}<0.01)$. Bleeding was observed in 2 patients in the CCBDE group, but none in the LCBDE group. Of these two patients, one needed further surgery, while the other was managed conservatively. Reasons for re-operation were bile leakage, drain dislocation, acute abdomen signs and bleeding. 11 (6.7\%) patients from the laparoscopic group and $7(6 \%)$ patients in the conventional group needed second surgery, but there was no statistical significance between the groups $(\mathrm{p}=0.821)$. In terms of stone extraction, the LCBDE group had more success $(93.9 \%$ vs $82.8 \%, \mathrm{p}<0.01)$ and their length of hos- 
pital stay was shorter $(6.3 \pm 3.9$ days vs $10.9 \pm 6.8, \mathrm{p}<0.01)$.

Mortality was recorded in $2(1.2 \%)$ patients in the laparoscopic group: one due to severe cholangitis and the second due to exacerbation of comorbidities and multiple organ failure. Mortality also occurred also in $7(6 \%)$ patients in the CCBDE group ( $p=0.036)$ : 6 patients with severe cholangitis and 1 patient with severe pancreatitis.

ERCP and sphincterotomies were performed in 33 (11.7\%) of 280 patients in the postoperative period due to retained stone or bile leakage. In the early post-op period, 12 (7.3\%) patients in the laparoscopic group and $21(18.1 \%)$ patients in the conventional group required ERCP followed by a sphincterotomy or stone extraction $(\mathrm{p}=0.006)$ (Table 3$)$.

\section{Discussion}

The occurrence of gallstones is directly proportional to age and its frequency is approximately 1:3 in patients over 70 years old. ${ }^{[6]}$ Bile duct stones are detected in $9 \%-14 \%$ of these patients and are considered to be the second most common complication of gallbladder stones. ${ }^{[7]}$

The main treatment methods for choledocholithiasis include LC+ERCP, CCBDE and LCBDE. LC+ERCP prior to or after the operation is still the most preferred treatment method used by surgeons and has $85 \%-95 \%$ success rate. ${ }^{[8]}$ However, contrary to these successful results, ERCP can lead to life threatening complications at a rate of $15 \%$. These complications are pancreatitis, bleeding, perforation, cholangitis and in addition, recurrent attacks of cholangitis, papilla stenosis and recurrent bile duct stones. ${ }^{[9]}$ In addition, it is argued that sphincterotomy may eventually cause biliary tract cancer due to chronic inflammation. ${ }^{[10]}$

The use of LCBDE has gradually increased over the last 20 years and has become one of the main treatment methods for choledocholithiasis. It is believed to offer singlestage surgery, minimal hospitalization and a higher success rate. In the literature, there are still very few studies comparing the results of laparoscopic and conventional common bile duct exploration. Reasons for LCBDE being less preferred in the past can be categorized as lack of experience, the scarcity of experienced personnel or lack of necessary equipment . ${ }^{[1]}$

In a study conducted by Grubnik et al., ${ }^{[5]}$ a comparison of complication results showed that wound infection and the need for transfusion were more common in the CCBDE group.In this study, residual stones were not categorized

\section{Tablo 3. Comparision of clinical outcomes of laparoscopic versus conventional CBDE}

\begin{tabular}{|c|c|c|c|c|}
\hline & & LCBDE & СCBDE & $p$ \\
\hline Operation time ( $\mathrm{n}$ & & 120.1 & 169.3 & $<0.01$ \\
\hline Morbidity, n (\%) & & $15(9.1)$ & $28(24.1)$ & $<0.01$ \\
\hline Re-operation, n & & $11(6.7)$ & $7(6)$ & 0.821 \\
\hline Length of hospita & (day), mean \pm sd & $6.3 \pm 3.9$ & $10.9 \pm 6.8$ & $<0.01$ \\
\hline Postoperative sfi & otomy, n (\%) & $12(7.3)$ & $21(18.1)$ & 0.006 \\
\hline Mortality, n (\%) & & $2(1.2)$ & $7(6)$ & 0.036 \\
\hline Drain dislocation & & $1(0.6)$ & $3(2.6)$ & 0.31 \\
\hline Wound infection & & $1(0.6)$ & $12(10.3)$ & $<0.01$ \\
\hline Bile leakage & & $8(4.9)$ & $5(4.3)$ & 0.824 \\
\hline Residual stone & & $10(6.1)$ & $20(17.2)$ & 0.003 \\
\hline Complications, $\mathrm{n}$ & & 21 (12.8) & $42(36.2)$ & $<0.01$ \\
\hline Clavien & 1 & 3 & 15 & \\
\hline Dindo & 2 & - & 1 & \\
\hline Classification & $3 \mathrm{~A}$ & 9 & 21 & \\
\hline (n) & $3 B$ & 9 & 5 & \\
\hline & $4 \mathrm{~A}$ & - & - & \\
\hline & $4 \mathrm{~B}$ & - & - & \\
\hline & 5 & 2 & 7 & \\
\hline
\end{tabular}


as a complication, giving an overall complication rate of $5 \%$ in the laparoscopic group and $12.7 \%$ in the conventional group. In our study, also excluding retained stones, the overall complication rate was $6.5 \%$ in the laparoscopic group and 19\% in the conventional group. In Grubnik's study, no difference was observed between the groups in terms of operation time; however, we found the operation time for LCBDE to be on average 49 minutes shorter than that of CCBDE.

In a study by Paganini et al. ${ }^{[12]}$ of 284 cases, the results of laparoscopic exploration stone extraction were found to be more successful than the combination of cholecystectomy following ERCP.In a study by Gong et al., ${ }^{[13]}$ stone extraction success by LCBDE was found to be $91.7 \%$. Similarly, throughout the literature, the overall success rate is $93.5 \%$, with the majority of series rated over $90 \%$ being obtained through choledochotomy. In our study, choledochotomy was preferred as the main laparoscopic exploration technique and stone extraction was successful in $93.9 \%$ of the patients.

In a study by Halawani et al., ${ }^{[14]}$ CCBDE was found to be associated with increased mortality, morbidity, bleeding and re-operation. In our study, mortality and morbidity rates were lower in the laparoscopic exploration group than in the conventional group, but there was no significant difference between the groups in terms of re-operation and post-operative bleeding. In the same study, retained bile duct stones and related complications were reported to be 2.8 times higher in the laparoscopic group than in the conventional group. However, unfortunately, bile duct exploration techniques and biliary reconstruction methods were not mentioned. In our study, in contrast to this situation, the residual stone rate was 2.8 times higher in the conventional group than in the laparoscopic group. Darrien et al. ${ }^{[15]}$ found in his study, the retained stone rate was $10 \%$ in the conventional exploration group and $16 \%$ in the laparoscopic exploration group. In our study, contrary to this, the rate of retained stone was $6.1 \%$ in the laparoscopic group and $17.2 \%$ in the conventional group. We attribute this result to the fact that in our study a high success rate of stone extraction was achieved after performing a full exploratory checkup in all patients in the laparoscopic group following their choledochotomy. However, no post-exploratory checkup was performed in the conventional group even after an emergency choledocoscope or a cholangiography exploration. In our opinion, as follow up to choledochoscope exploration, a thorough check of the distal bile duct right up to the duodenum and the proximal until the intrahepatic biliary tract can minimize the risk of retained stones.

In the literature, morbidity rates following LCBDE have been recorded as between $7 \%-19 \%$ (average $8 \%$ ). ${ }^{[16]}$ Parallel to our results, there are studies showing that the morbidity rate may be lower in LCBDE. ${ }^{[5]}$ In our study, the morbidity rate of the laparoscopic group was lower. Also, in terms of hospitalization time, mortality rate, operation time and postoperative endoscopic sphincterotomy requirement, LCBDE results were superior.

One of the most common complications of laparoscopic choledochotomy is bile leakage with a reported rate of $6 \%-14.6 \%$ in the literature. ${ }^{[17]}$ In the study conducted by Nuria et al., ${ }^{[18]}$ postoperative results from 160 patients receiving primary suture closure after choledectomy were evaluated.It was not specified whether the operations were emergency or elective. The rate of bile leakage was found to be $6.8 \%$. In our study, this percentage was much lower: $4.9 \%$ in the laparoscopic group and $4.3 \%$ in the conventional group. In the laparoscopic group, 1 patient $(0.6 \%)$ developed pancreatitis post-surgery.

The choice of biliary reconstruction technique is a current topic of discussion and differs among surgeons. Recent studies have established that the primary closure method used in the choledochotomy of the large CBD does not increase the risk of biliary stricture. ${ }^{[19]}$ On the other hand, Ttube drainage is also a popular reconstruction technique considering the advantages it provides for the drainage of a partially cleaned or edematous bile duct, in removing retained stones from the tract and performing postoperative cholangiography. ${ }^{[20]}$ However, the T-tube may cause an inflammatory reaction along the drainage tract, creating a biliocutaneous fistula. The risk of developing biliary peritonitis following the removal of the T-tube has been reported to be between $2.5 \%-19.6 \%$ with a $4.3 \%$ reoperation and a high mortality rate. ${ }^{[21]}$ Moreover, T-tube drainage has been under review for some time due to its $15 \%-28 \%$ complication rate in both conventional and laparoscopic operations. The most common complications are cholangitis, tube dislocation and bile leakage. Zhang et al. ${ }^{[22]}$ compared T-tube drainage and primary closure techniques following LCBDE and concluded that the cost, operation time, postoperative complication and biliary complication rates were lower in patients who received primary closure than in patients who received a T-tube; primary closure was emphasized as a safe and effective 
reconstruction technique. Augustin et al. ${ }^{[23]}$ concluded that transpapillary stenting could reduce T-tube related complications, increase patient comfort and shorten the length of postoperative hospitalization. In our study, 11 patients in the laparoscopic exploration group received an endobiliary stent. Further studies comparing this method with other reconstruction techniques should be carried out for clarification.

Sirinek et al. ${ }^{[2]}$ stated that general surgical assistants graduating over the last 30 years had not been exposed to sufficient intraoperative cholangiography and common bile duct exploration, thus raising concerns about the educational level of young surgeons. We believe that this issue should be taken into consideration and opportunities to develop laparoscopic skills such as CBDCE, LBDCE and intraoperative cholangiography should be increased during surgical training.

As our study is retrospective, we were not able to randomize the groups, which can be considered a flaw in this study.

\section{Conclusion}

Due to its minimally invasive nature, a reduction in scar tissue and pain, we conclude that laparoscopic exploration is a significantly safer and more efficient method than conventional exploration. This method should be preferred in the surgical treatment of choledocholithiasis due to its advantages in terms of a reduction in operation time, retained stones, morbidity, mortality, wound infection rate and length of hospital stay.

\section{Disclosures}

Ethichs Committee Approval: The study was approved by University of Health Science Prof. Dr. Cemil Taşçığlu State Hospital Ethics Committee (22.11.2016/546).

Peer-review: Externally peer-reviewed.

Conflict of Interest: None declared.

Authorship Contributions: Concept - M.C.A.; Design M.C.A., E.K.; Supervision - E.K, S.R.K.; Materials - M.C.A.; Data collection and/or processing - M.C.A.; Analysis and/ or interpretation - M.C.A., E.K.; Literature search - M.C.A.; Writing - M.C.A.; Critical review - M.C.A., E.K., S.R.K.

\section{References}

1. Ko CW, Lee SP. Epidemiology and natural history of common bile duct stones and prediction of disease. Gastrointest Endosc 2002;56:S165-9.[CrossRef]
2. Sandha J, van Zanten SV, Sandha G. The Safety and Efficacy of Single-Operator Cholangioscopy in the Treatment of Difficult Common Bile Duct Stones after Failed Conventional ERCP. J Can Assoc Gastroenterol 2018;1:181-90. [CrossRef]

3. Pan L, Chen M, Ji L, Zheng L, Yan P, Fang J, ET AL. The Safety and Efficacy of Laparoscopic Common Bile Duct Exploration Combined with Cholecystectomy for the Management of Cholecysto-choledocholithiasis: An Up-to-date Meta-analysis. Ann Surg 2018;268:247-53. [CrossRef]

4. Wang P, Li ZS, Liu F, Ren X, Lu NH, Fan ZN, et al. Risk factors for ERCP-related complications: a prospective multicenter study. Am J Gastroenterol 2009;104:31-40. [CrossRef]

5. Grubnik VV, Tkachenko Al, llyashenko VV, Vorotyntseva KO. Laparoscopic common bile duct exploration versus open surgery: comparative prospective randomized trial. Surg Endosc 2012;26:2165-71. [CrossRef]

6. Freitas ML, Bell RL, Duffy AJ. Choledocholithiasis: evolving standards for diagnosis and management. World J Gastroenterol 2006;12:3162-7. [CrossRef]

7. Dasari BV, Tan CJ, Gurusamy KS, Martin DJ, Kirk G, McKie $\mathrm{L}$, et al. Surgical versus endoscopic treatment of bile duct stones. Cochrane Database Syst Rev 2013;2013:CD003327.

8. van Dijk $A H$, Lamberts $M$, van Laarhoven $C J$, Drenth JP, Boermeester MA, de Reuver PR. Laparoscopy in cholecysto-choledocholithiasis. Best Pract Res Clin Gastroenterol 2014;28:195-209. [CrossRef]

9. Ong TZ, Khor JL, Selamat DS, Yeoh KG, Ho KY. Complications of endoscopic retrograde cholangiography in the postMRCP era: a tertiary center experience. World J Gastroenterol 2005;11:5209-12.

10. Schreurs WH, Juttmann JR, Stuifbergen WN, Oostvogel HJ, van Vroonhoven TJ. Management of common bile duct stones: selective endoscopic retrograde cholangiography and endoscopic sphincterotomy: short- and long-term results. Surg Endosc 2002;16:1068-72. [CrossRef]

11. Shelat VG, Chia VJ, Low J. Common bile duct exploration in an elderly Asian population. Int Surg 2015;100:261-7. [CrossRef]

12. Paganini AM, Lezoche E. Follow-up of 161 unselected consecutive patients treated laparoscopically for common bile duct stones. Surg Endosc 1998;12:23-9. [CrossRef]

13. Khan MR, Naureen S, Hussain D, Azami R. Management outcome of residual common bile duct stones at Aga Khan University Hospital. J Ayub Med Coll Abbottabad 2005;17:710.

14. Halawani HM, Tamim H, Khalifeh F, Mailhac A, Taher A, Hoballah J, et al. Outcomes of Laparoscopic vs Open Common Bile Duct Exploration: Analysis of the NSQIP Database. J Am Coll Surg 2017;224:833-40.e2. [CrossRef]

15. Darrien JH, Connor K, Janeczko A, Casey JJ, Paterson-Brown S. The Surgical Management of Concomitant Gallbladder and Common Bile Duct Stones. HPB Surg 2015;2015:165068.

16. Berthou JCh, Dron B, Charbonneau P, Moussalier K, Pellissier L. Evaluation of laparoscopic treatment of common bile duct stones in a prospective series of 505 patients: indications and results. Surg Endosc 2007;21:1970-4. [CrossRef] 
17. Sharma A, Dahiya P, Khullar R, Soni V, Baijal M, Chowbey PK. Management of common bile duct stones in the laparoscopic era. Indian J Surg 2012;74:264-9. [CrossRef]

18. Estellés Vidagany $\mathrm{N}$, Domingo Del Pozo $\mathrm{C}$, Peris Tomás N, Díez Ares JÁ, Vázquez Tarragón A, Blanes Masson F. Eleven years of primary closure of common bile duct after choledochotomy for choledocholithiasis. Surg Endosc 2016;30:1975-82. [CrossRef]

19. Campbell-Lloyd AJ, Martin DJ, Martin IJ. Long-term outcomes after laparoscopic bile duct exploration: a 5-year follow up of 150 consecutive patients. ANZ J Surg 2008;78:4924. [CrossRef]

20. Ahmed M, Diggory RT. Case-based review: bile peritonitis after T-tube removal. Ann R Coll Surg Engl 2013;95:383-5. [CrossRef]
21. Maghsoudi H, Garadaghi A, Jafary GA. Biliary peritonitis requiring reoperation after removal of T-tubes from the common bile duct. Am J Surg 2005;190:430-3. [CrossRef]

22. Zhang WJ, Xu GF, Wu GZ, Li JM, Dong ZT, Mo XD. Laparoscopic exploration of common bile duct with primary closure versus T-tube drainage: a randomized clinical trial. J Surg Res 2009;157:e1-5. [CrossRef]

23. Dietrich A, Alvarez F, Resio N, Mazza O, de Santibañes E, Pekolj $\mathrm{J}$, et al. Laparoscopic management of common bile duct stones: transpapillary stenting or external biliary drainage? JSLS 2014;18:e2014.00277. [CrossRef]

24. Sirinek KR, Willis $R$, Schwesinger WH. Who Will Be Able to Perform Open Biliary Surgery in 2025? J Am Coll Surg 2016;223:110-5. [CrossRef] 